九州大学学術情報リポジトリ

Kyushu University Institutional Repository

\title{
Studies on Manufacturing of Wooden Flat Pallet by Staggered Connection Using Sugi Compressed- dowel and its Process
}

Uno, Akari

Laboratory of Woodworking, Department of Technology, Fukuoka University of Education

Ohuchi, Takeshi

Laboratory of Woodworking, Department of Technology, Fukuoka University of Education

Fuj imoto, Noboru

Sustainable Bioresources Science, Agro-environmental Sciences, Faculty of Agriculture, Kyushu University

https://doi.org/10.5109/22069

出版情報：九州大学大学院農学研究院紀要. 57 (1)，pp. 175-179，2012-02. Faculty of Agriculture， Kyushu University

バージョン :

権利関係 : 


\title{
Studies on Manufacturing of Wooden Flat Pallet by Staggered Connection Using Sugi Compressed-dowel and its Process
}

\author{
Akari UNO ${ }^{1}$, Takeshi OHUCHI ${ }^{1 *}$ and Noboru FUJIMOTO \\ Laboratory of Wood Material Technology, Sustainable Bioresources Science, \\ Department of Agro-environmental Sciences, Faculty of Agriculture, \\ Kyushu University, Fukuoka 812-8581, Japanese \\ (Received October 31, 2011 and accepted November 9, 2011)
}

\begin{abstract}
In this study, we manufactured three types of the wooden flat pallet with different in the number of sheets of the top board of the backside. First type (7-7 type); the number of sheets of the top board of the backside was seven pieces. Second type ( $7-5$ type); the number of that was five pieces. Third type (7-3 type); the number of that was three pieces. The number of the surface of three types was all seven pieces. In the manufacturing, the staggered connections using sugi (Cryptomeria japonica D. Don) compresseddowel were applied to the pallet, and the evaluation test in accordance with Japanese Industrial Standard (JIS Z 0602) was performed. The main results are summarized as follows: The pallet weight became small in decreasing the number of sheets of the top board and the difference of the weight was about $6 \mathrm{kgf}(20 \%)$. The bend rate in the bending test for each type pallet was smaller than $2.5 \%$ of the standard value of JIS. The residual bend rate in the bending test for each type pallet was also smaller than $0.5 \%$ of the standard value of JIS. Therefore, it was confirmed that the condition as the pallet of both the bend rate and the residual bend rate was cleared. In each type pallet, the condition as the pallet in the change rate of the diagonal length in the fall down test was cleared because the change rate of the each value was smaller than $3 \%$ of the standard value of JIS. The remarkable difference of the withdrawal strength of each type pallet in the pull-out test for the staggered connections using sugi compressed dowel was not recognized. Moreover, it became clear that approximately 56 minutes in manufacturing process of one pallet can be shortened and the manufacturing cost can be decreased because four top boards of the backside of the pallet were decreased.
\end{abstract}

Key words: staggered connection, sugi compressed-dowel, wooden flat pallet

\section{INTRODUCTION}

Recently, the advanced utilization of sugi (Cryptomeria japonica D. DON) is especially demanded to use the domestic lumber effectively. Then, many researches and developments to use sugi effectively were performed. Authors also performed the research and development for the binder-less connection using sugi compressed-dowel previously for sugi effective utilization (Ohuchi et al., 2008).

In main aim of this research, the possibility of the practical application of the binder-less connection using sugi compressed-dowel is examined. Based on the data of sugi compressed-dowel obtained in our previous studies (Ohuchi et al., 2008), this method was applied to the connection of the top board and the beam of the wooden flat pallet, and the possibility of the practical application for the connection of the wooden flat pallet was examined.

Authors previously manufactured the sugi flat pallet by the binder-less connection using sugi compressed dowel for the connection part of the top board and the beam, and performed the evaluation tests (Ohuchi et al., 2011). From these results, the problems in the manufacturing of the sugi flat pallet were caused on weight, the processing time, and the cost though the strength per-

${ }^{1}$ Laboratory of Woodworking, Department of Technology, Fukuoka University of Education

* Corresponding author (E-mail: tohuchi@fukuoka-edu.ac.jp) formance showed the performance equal with the pallet of the nail connection. To solve these problems, we were considered to decrease the number of sheets of the top board.

In this study, to decrease the number of sheets of the top board, we manufactured the sugi flat pallet with different number of sheets of the top board on the backside of the pallet. In the manufacturing experiment, when the number of sheets of the top board decreases, the decrease in strength performance of pallet was considered. Then, the sugi flat pallet by staggered connections using sugi compressed-dowel was manufactured to prevent this decrease of strength performance, and the evaluation test in accordance with Japanese Industrial Standard (JIS Z 0602) was performed. From the obtained results, the possibility of practical application was examined. Moreover, the manufacturing process of the pallet was examined.

\section{MATERIALS AND METHODS}

\section{Test pallet}

The wooden flat pallets of square type (1100x $1100 \mathrm{~mm}$ ) were manufactured. In the manufacturing of the pallet, the mean specific gravities and moisture content (MC) of sugi (Cryptomeria japonica D. DON) top board and sugi beam were 0.40 and $12.5 \%$, respectively. Three types pallet in this study were manufactured. First type (7-7 type); the number of sheets of the top board of the surface and backside was seven pieces. 
Second type (7-5 type); the number of sheets of the top board of the surface was seven pieces and that of the backside was five pieces. Third type (7-3 type); the number of sheets of the top board of the surface was the same number of type $7-7,7-5$ and that of the backside was three pieces. Thus, each three pallets of three types (7-7, 7-5, 7-3 type) with different in the number of sheets of the top board on the backside was manufactured as shown in Fig. 1.

The top board and the beam of the pallet were connected with the binder-less connection using sugi compressed-dowel. This connection is a method using the power to occur when the compressed-dowel starts absorbing moisture and turns into original shape (Ohuchi et al., 2008). This method has novelty in a point to connect without using adhesive. Therefore, it is the new type connection to make the best use of nature material. In this connection method, recycling is easy and environment is unaffected.
The raw material of the compressed-dowel was sugi. The mean MC was $11.1 \%$ and the mean specific gravities was 0.37. Sugi specimen for the compressed-dowel was heated for $30 \mathrm{sec}$ with a micro wave heating device, and was pressed in the radial direction with a hot press. In the hot press conditions, the plate temperature was adjusted to $180^{\circ} \mathrm{C}$, and the hot press time was adjusted to $300 \mathrm{sec}$. The thickness was provided by using a distance-bar of $15 \mathrm{~mm}$ thick. After hot pressing, the specimen was cured at room for two week, and was processed into the dowel of $12 \mathrm{~mm}$ in diameter and $60 \mathrm{~mm}$ in length.

The enhanced hole for the binder-less connection was processed by using Computer Numerically Controlled router (CNC router). When the number of sheets of the top board decreased, the decrease in strength performance of pallet was considered. Then, the flat pallet by staggered connections using sugi compressed-dowel was manufactured as shown in Fig. 2. (a) 7-7 type

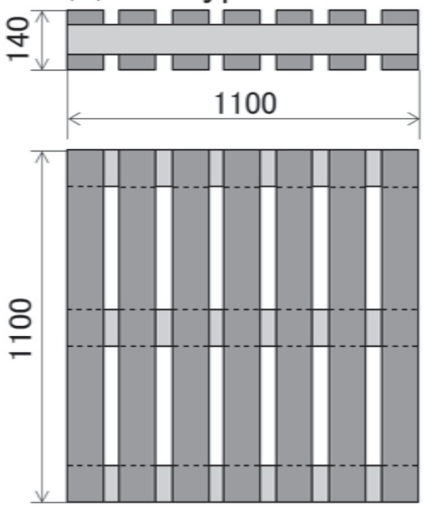

(b) 7-5 type
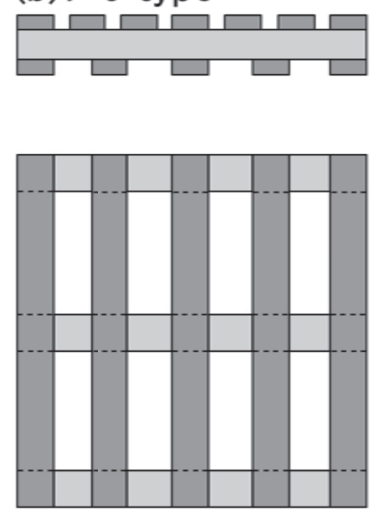

(c)7-3 type
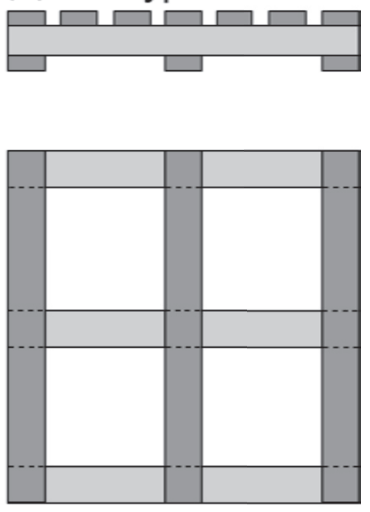

(unit: mm)

Fig. 1. Three types pallet manufactured in this study.

(a) Staggered connections
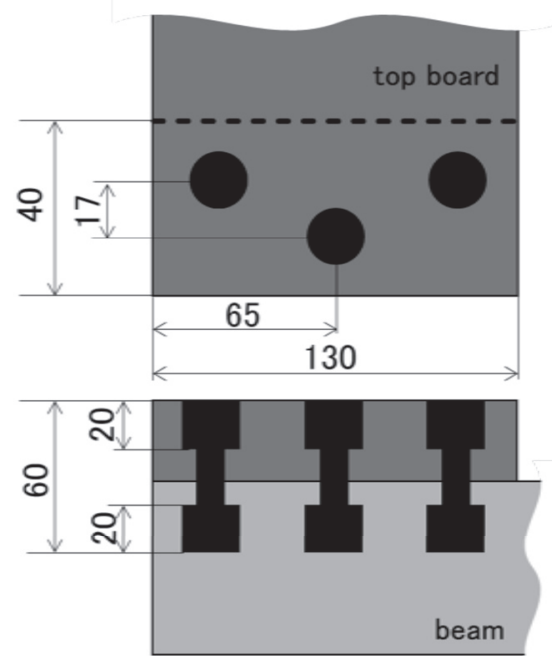

\section{(b) Control}
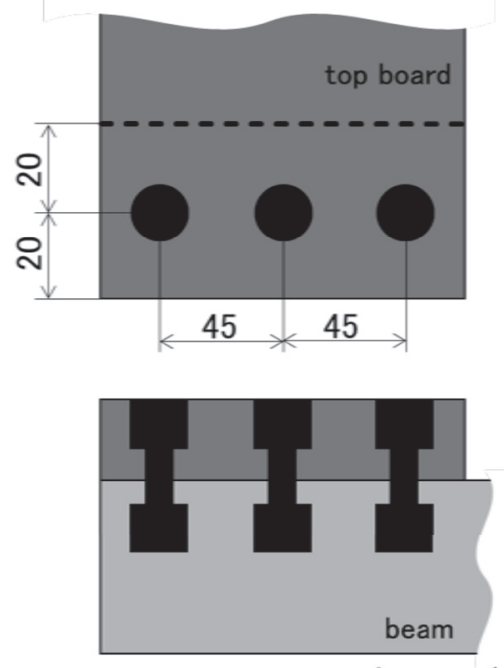

(unit: $\mathrm{mm}$ )

Fig. 2. Schematic diagram of staggered connections in this study. 


\section{Evaluation test}

The manufactured flat pallets were cured for two weeks and were then weighed with a digital platform scale. In addition, the evaluation test was performed to

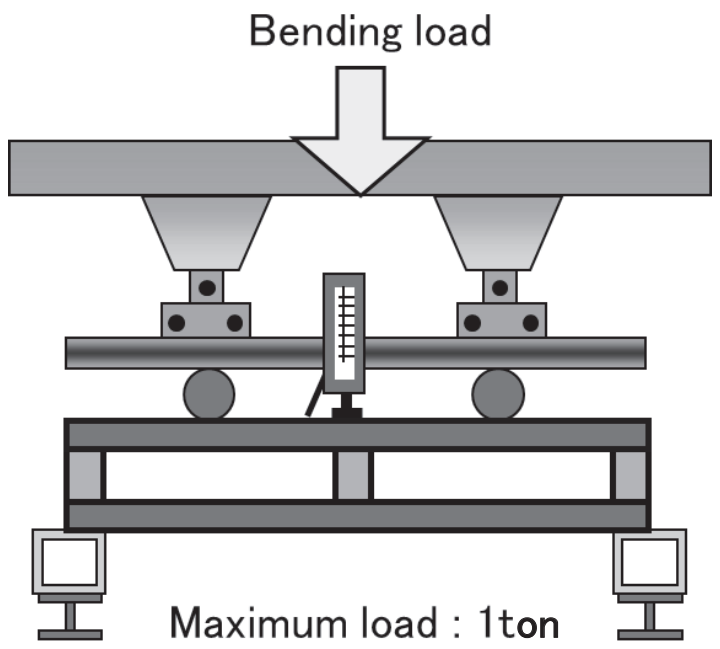

Fig. 3. Outline of bending test.

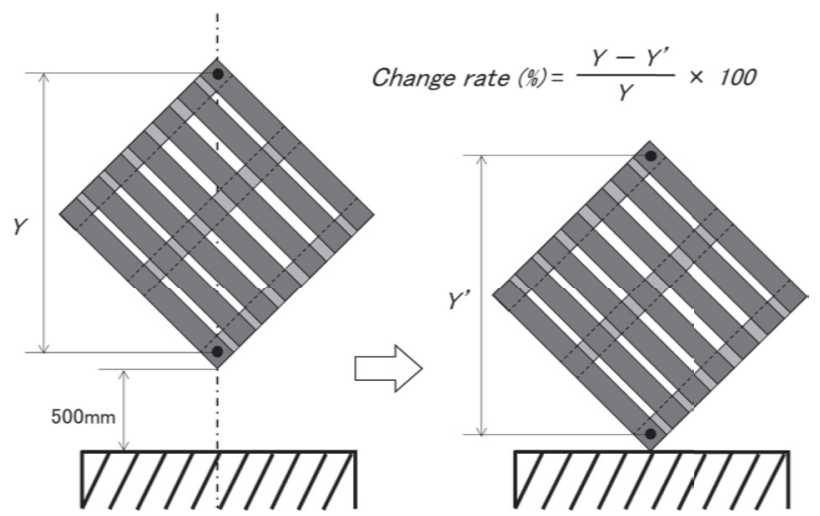

Fig. 4. Outline of fall down test.

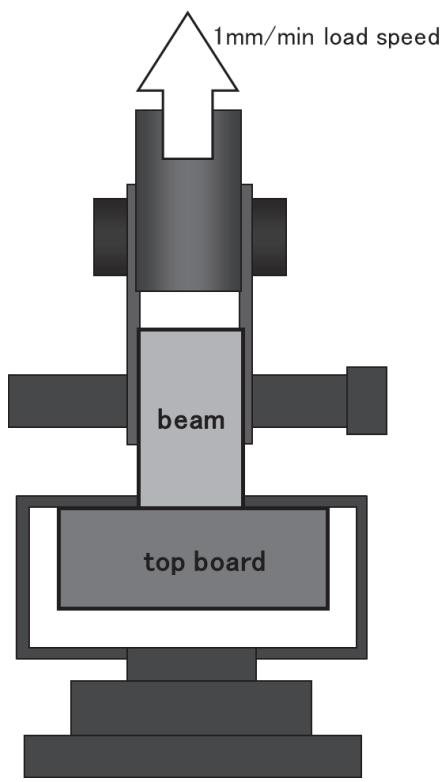

Fig. 5. Outline of pull-out test in the binder-less connection part. examine the strength performance of the pallet. In this test, the bending test and the fall down test were performed in accordance with Japanese Industrial Standard (JIS Z 0602). The bend rate and the residual bend rate in the bending test were examined as shown in Fig. 3. The change rate of the diagonal length in the fall down test was examined as shown in Fig. 4. Moreover, to examine the performance of the binder-less connection with sugi compressed-dowel after the evaluation tests, the pull-out test of the binder-less connection part composed of the top board and beam was performed as shown in Fig. 5.

\section{RESULTS AND DISCUSSION}

\section{Weight of pallet}

Figure 6 shows the average weight of the pallet in each type 7-7, 7-5, and 7-3. From this result, it was confirmed that the weight of pallet became small in decreasing the number of sheets of the top board, and the difference in weight was about $6 \mathrm{kgf}$.

\section{Bending strength properties}

For the sake of comparison of the performance of the manufactured pallet in this study, the results obtained in our previous study (Ohuchi et al., 2011) are shown as control value in the following figures (Fig. 7-10).

Figure 7 shows the bend rate in each pallet. The

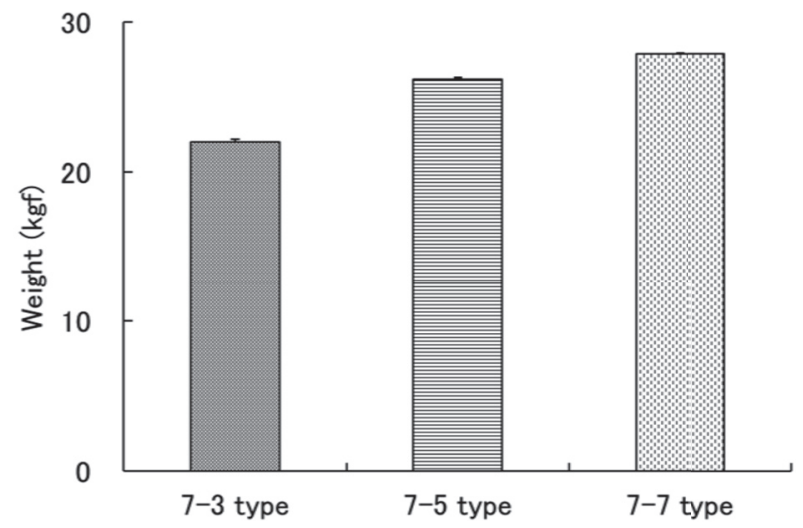

Fig. 6. Weight of three types pallet.

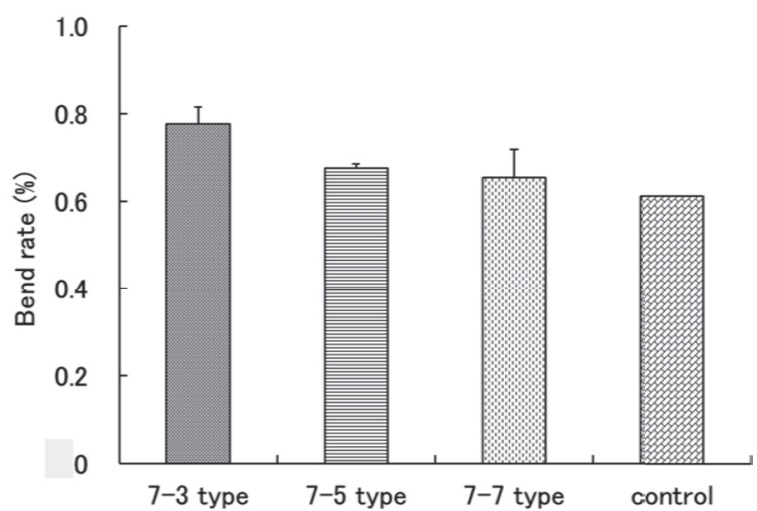

Fig. 7. Bend rate of each type pallet in this bending test. 
bend rate of the control pallet showed the smallest value. Moreover, that of 7-5 and 7-7 types was almost the same value. That of each type pallet was smaller than $2.5 \%$ of the standard value of JIS.

The residual bend rate in each pallet is shown in Fig. 8. That of the control pallet showed the smallest value as well as the bend rate. That of 7-5 type showed the comparatively smaller value. Moreover, those of 7-3 and 7-7 types were almost the same value, and the values showed large value compared with other types. That of each type pallet was also smaller than $0.5 \%$ of the standard value of JIS. From the above-mentioned results of the bending test, it was confirmed that the conditions as the pallet of both the bend rate and the residual bend rate were cleared.

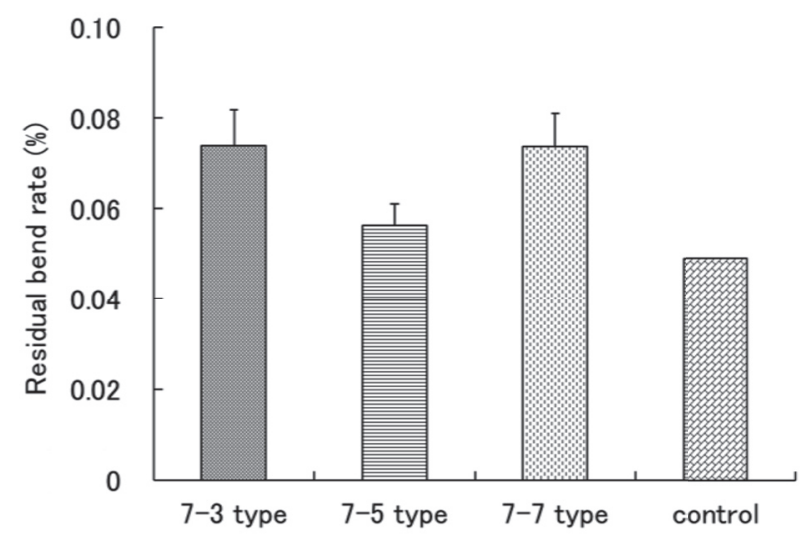

Fig. 8. Residual bend rate of each type pallet in this bending test.

\section{Change rate of diagonal length in fall down test}

Figure 9 shows the change rate of the diagonal length in the fall down test. In the change rate of $7-5$ type, a slightly small value was shown, and the change rate in other types showed almost the same value. However, in each type pallet, the condition of the change rate as the pallet was cleared because the each value of the change rate was smaller than $3 \%$ of the standard value of JIS.

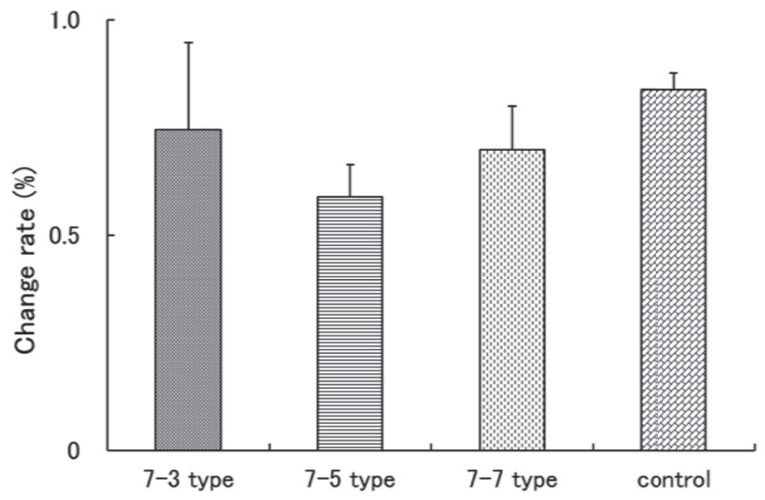

Fig. 9. Change rate of each type pallet in this fall down test.

\section{Withdrawal strength}

Figure 10 shows the withdrawal strength of each type pallet in the pull-out test. The remarkable difference in withdrawal strength was not recognized in each condition. Moreover, in the range of this experiment condition, the correlation was not admitted between the results of the evaluation test in accordance with JIS and the withdrawal strength of each condition.

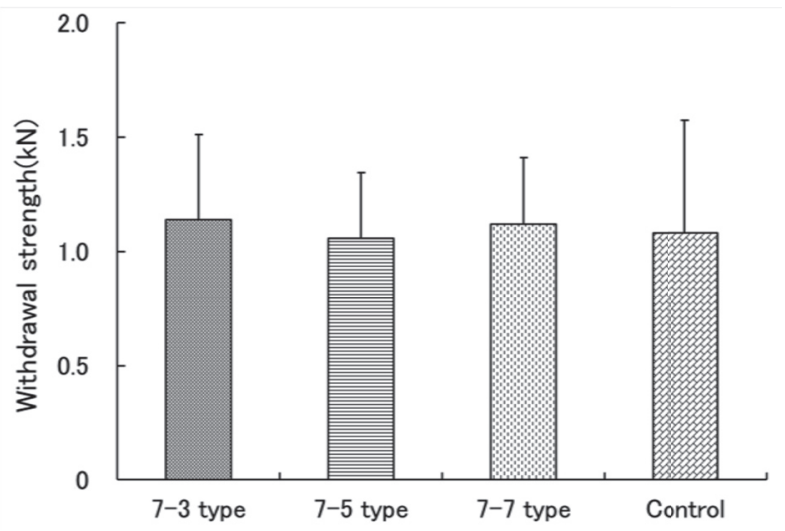

Fig. 10. Withdrawal strength of each type pallet in this pull-out test.

\section{Manufacturing process}

In the manufactured pallet in this study, it was cleared that four top boards were decreased in maximums compared with a usual pallet. The time required for the enhanced hole processing of the binder-less connection was shortened due to the decrease of four top boards. Then, the processing time of the enhanced hole was examined. This processing time is limited to the enhanced hole processing.

In the number of enhanced holes of one pallet, $7-7$ type is 252 pieces, $7-5$ type is 216 pieces, and 7-3 type is 180 pieces. Therefore, 72 pieces enhanced hole processing can be decreased in maximums. Moreover, in the consideration of the processing time of one pallet, $7-3$ type is about 60 minutes, 7-5 type is about 90 minutes, and 7-7 type is about 116 minutes. Thus, approximately 56 minutes can be shortened in maximums.

From the above-mentioned, the manufacturing cost can be decreased because the power consumption of the woodworking machinery (CNC router) in the enhanced hole processing is suppressed. However, in manufacturing with the conventional nail joint, the required manufacturing time of one pallet is from about 8 to $10 \mathrm{~min}$ utes. Therefore, it will be necessary to improve the manufacturing process in the future.

\section{CONCLUSIONS}

In this study, we manufactured three types (7-7, 7-5, 7-3 type) of sugi flat pallet with different in the number of sheets of the top board on the backside of the pallet. In the manufacturing, the staggered connections using sugi compressed-dowel were applied to the pallet, and the evaluation test in accordance with Japanese Industrial 
Standard (JIS Z 0602) was performed. The main results are summarized as follows:

1) The pallet weight became small in decreasing the number of sheets of the top board and the difference of the weight was about $6 \mathrm{kgf}$.

2) The bend rate in the bending test for each type pallet was smaller than $2.5 \%$ of the standard value of JIS. The residual bend rate in the bending test for each type pallet was also smaller than $0.5 \%$ of the standard value of JIS. Therefore, it was confirmed that the condition as the pallet of both the bend rate and the residual bend rate was cleared.

3) In each type pallet, the condition as the pallet of the change rate of the diagonal length in the fall down test was cleared because the change rate of the each value was smaller than $3 \%$ of the standard value of JIS.

4) The remarkable difference of the withdrawal strength of each type pallet in the pull-out test for the stag- gered connections using sugi compressed dowel was not recognized.

5) The enhanced hole processing of 72 pieces can be decreased in maximums because four top boards of the backside of one pallet were decreased. Therefore, it was considered that approximately 56 minutes in manufacturing process of one pallet can be shortened in maximums and the manufacturing cost can be decreased.

\section{REFERENCES}

Ohuchi T, Kinjyo M, Murase Y, and Ikeda M (2008), Withdrawal Strength of New Type Connection with Sugi Compresseddowel, Conference Proceedings of $10^{\text {th }}$ WCTE 2008, CD-ROM p. 204

Ohuchi T and Uno A (2011), Production of Wooden Flat Pallet by Using Sugi Compressed-dowel, Abstracts of the 61st Annual Meeting of the Japan Wood Research Society, p. 22 